\title{
PIC BASED WATT-METER USING AN ANALOG MULTIPLIER
}

\author{
Alankar M. Salunkhe ${ }^{1}$, R R. Jagtap ${ }^{2}$ \\ ${ }^{I}$ Master of Engineering, Department of Electronics \& Telecommunication Annasaheb Dange College of Engineering \\ and Technology, Ashta, M.S., India \\ ${ }^{2}$ Associate Professor, Department of Electronics \& Telecommunication, Annasaheb Dange College of Engineering \\ and Technology, Ashta, M.S., India
}

\begin{abstract}
For a nation its Economical development depends widely on factors such as its education, industrial growth and many other factors and one of the most important factors amongst them is Energy consumption. Currently in our country we are facing problem such as losses in production, transmission and distribution of power which causes financial damage for everyone. In our country, there is great demand for electrical energy. This electrical energy is widely used in home as well as in various types of industries. For generation, transmission and distribution of the electrical energy cost is quite high. Due to this reason it is important to use and save the electrical energy efficiently, to reduce losses, and simultaneously the generation costs to protect the environment by reducing the power consumption. One of the most effective methods of increasing the savings and efficiency is power compensation. Power consumption is an important for all area that utilizes electrical energy. In most cases, the amount of electricity consumed by electronic and electrical appliances is not readily apparent. Many electronic appliances are produced with an information tag which tells us about its power consumption, but this is typically an average or maximum, and these appliances consume less or more power than information given on tag. Such devices such as solid state TVs, washing machines, Mixer and all other home appliances which often draw power even when they are in off state. In practice if a home appliance consume more power than its rated value then consumers must pay additional charges for monthly electricity bill. Therefore is is necessary to measure and monitor power consumption in household, an industry, particular locality at any certain time constant.
\end{abstract}

Keywords-Analog Multipliers, Power Measurement, Power Factor Measurement, Zcd, Etc.

$* * *$

\section{INTRODUCTION}

For production of home appliances and industrial equipment it is necessary that they can consume given rated power rating and maintain quality forever. Accurate measurement of power and other AC quantities is extremely important at all levels of the electrical power system, because for any device power consumption is more than its rated value then it causes increasing energy cost and also reduction in its performance also. Main goals of this paper is to improve the efficiency of the electric power system. In existing system requires monitoring of the system parameters such as voltage ,current power factor, rms voltage and rms current and based on value of these parameters calculate power and energy. The main parameters of the single phase and threephase electric power system are voltage, current, frequency, active power, reactive power, power factor, active energy and reactive energy. Continuously increase in cost of the electric energy forces us to design precise measuring devices with high quality and accuracy. Main objective of this paper is to design power meter that gives satisfactorily results for resistive as well as inductive loads in sinusoidal as well as non-sinusoidal conditions with best power quality. This instrument has requires less components as compared with existing power meters therefore it is less complex and can be installed in less area. In proposed paper electrical power is measured using analog Ic AD633. In order to calculate power of inductive and capacitive loads it is essential to calculate power factor. For pure resistive load there is no phase difference in voltage and current and for inductive and capacitive loads phase of current signal shifts with maximum of $\pm 90^{\circ}$ with respect to the voltage signal. This causes loss in power and energy consumption of many home appliances and industrial devices also. Alalog Multiplier IC AD633 has accuracy of $99 \%$ and can work normally in temperature range of 65 degree. As its name implies it multiplies two incoming analog voltage and analog current signals directly and produces analog output voltage that is proportional to relative power of devices. The output of multiplier low pass filtered and given to PIC Microcontroller Ic 18 F4550 . Proposed system does not require additional analog to digital converter circuitry because $18 \mathrm{~F} 4550$ has inbuilt ten bit analog to digital (ADC) converter. Finally power is calculated in software that is written in Micro-c Pro and displayed on LCD panel.

\section{OVERVIEW OF INSTRUMENT}

The overview and working of each section of proposed instrument is given in five sections as follows. Block diagram of proposed system is given in Fig. 1,

1) voltage and current transformers;

2) Four quadrant multiplier AD633;

3) zero crossing detector circuit

4) RC low-pass filter;

5) 18F4550 Microcontroller;

6) $16 \times 2$ LCD display 
Proposed system is divided into mainly five sections. This system is useful to measure power of high wattage electrical devices as well as low wattage home appliances. Proposed system can operate with low AC voltage as well as high AC voltage. Maximum current ranges were set at $16 \mathrm{~A} \mathrm{rms}$ and at $350 \mathrm{~V} \mathrm{rms}$ for the voltage, with a nominal power range of $2.0 \mathrm{~kW}$. The main heart of the wattmeter circuit is an analog multiplier that computes the four-quadrant product of ac line voltage and load current, gives output analog voltage that is proportional to average power consumed by load. This output signal is low-pass filtered using RC low pass filter to further reduce the ripple on the output signal. After low pass filtering this voltage signal is given to AD0 pin of $18 \mathrm{~F} 4550$ PIC microcontroller that converts analog signal into digital signal using inbuilt (ADC) converter. Power delivered to load is calculated using software coding in MIKRO-C PRO complier and display on 16x2 LCD pannel.

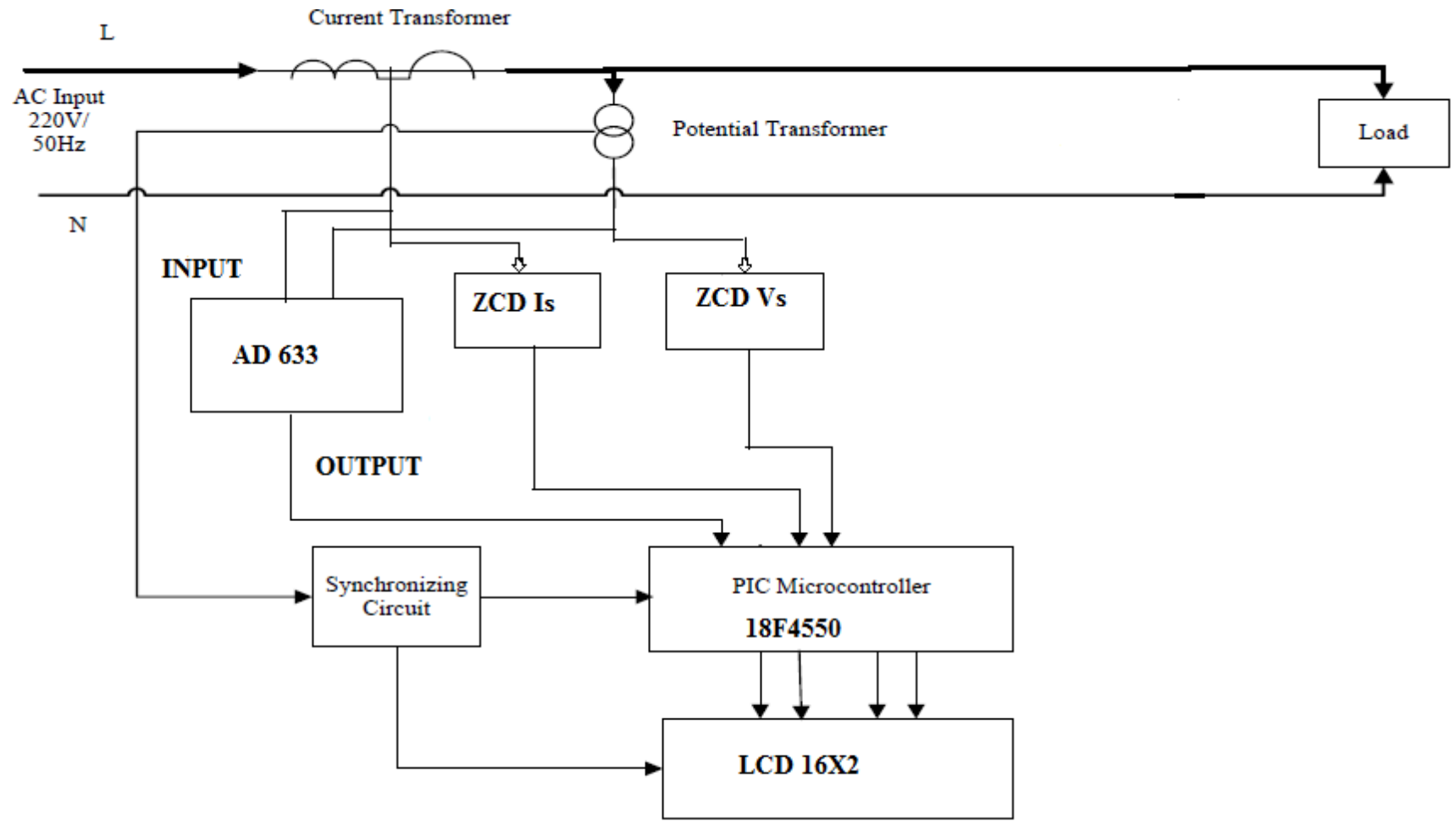

Fig.-1: Block diagram for the proposed power measurement system

\subsection{Voltage Measurement}

The voltage measurement is carried out by using a centretapped 12-0-12 voltage transformer which gives up to $13 \mathrm{~V}$ analog voltage signals and this voltage is lowered that can be acceptable for the AD633 Multiplier Ic. It can withstand maximum current of $5 \mathrm{~A}$. The voltage transformer can be chosen such that it has high reliability and long life.

\subsection{Current Measurement}

The current measurement is carried out using current transformer. CT has a current range of 0 to $25 \mathrm{~A}$ that is useful for single phase power measurement system. A burden resistor of $10 \mathrm{~K} \Omega$ is connected across output terminals of current transformer that gives maximum $10 \mathrm{~V}$ AC voltage as per load conditions that is acceptable by AD633 multiplier IC. Fig.2 shows current transformer used for proposed power measurement system.

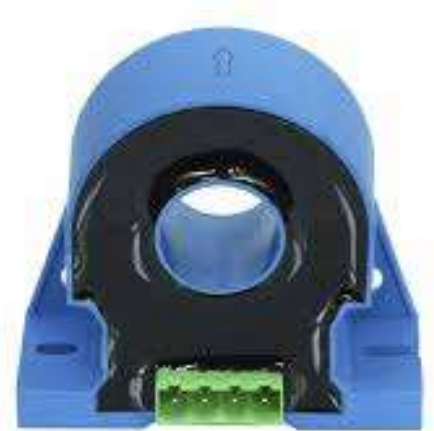

Fig.-2: CT used for the proposed power measurement system.

\subsection{Zero Crossing Detector (ZCD) Section}

The zero crossing detector is a circuit that converts incoming sine wave signal into output square wave signal. As its name implies in (ZCD) reference voltage is set to zero Output waveform zero crossing detector circuit shows when and in what direction an input voltage and current signal 
crosses zero volt. Microcontroller is programmed to detect this zero crossing of voltage and current signals and according to this calculation power factor is calculated. The mains AC voltage is given to voltage transformer and current is given to current transformer. The output of voltage and current transformer is lowered by using resistor and given to Op-Amp LM 358 and relative circuitry to detect zero crossing of both voltage and current signals.

LM 358 is eight pin op-amp Ic which operate with $5 \mathrm{~V}$ dc supply voltage and easily available Ic. Fig. 3 shows zero crossing detector circuit and Fig. 4 shows output of corresponding zero crossing detector circuit.

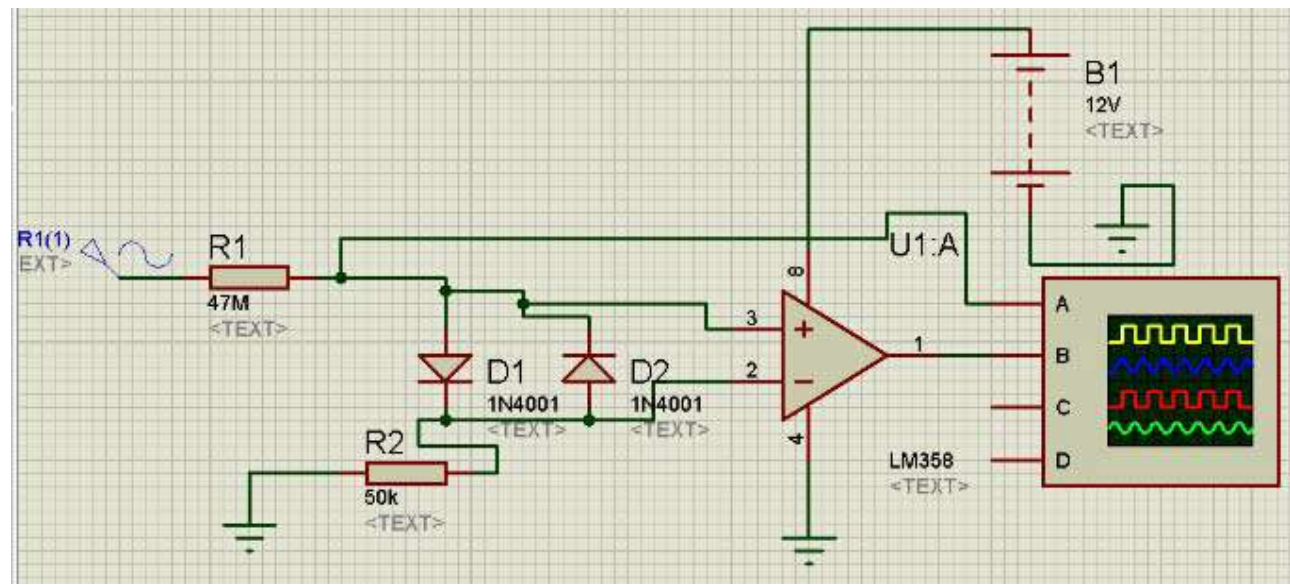

Fig.-3: Zero crossing detector circuit

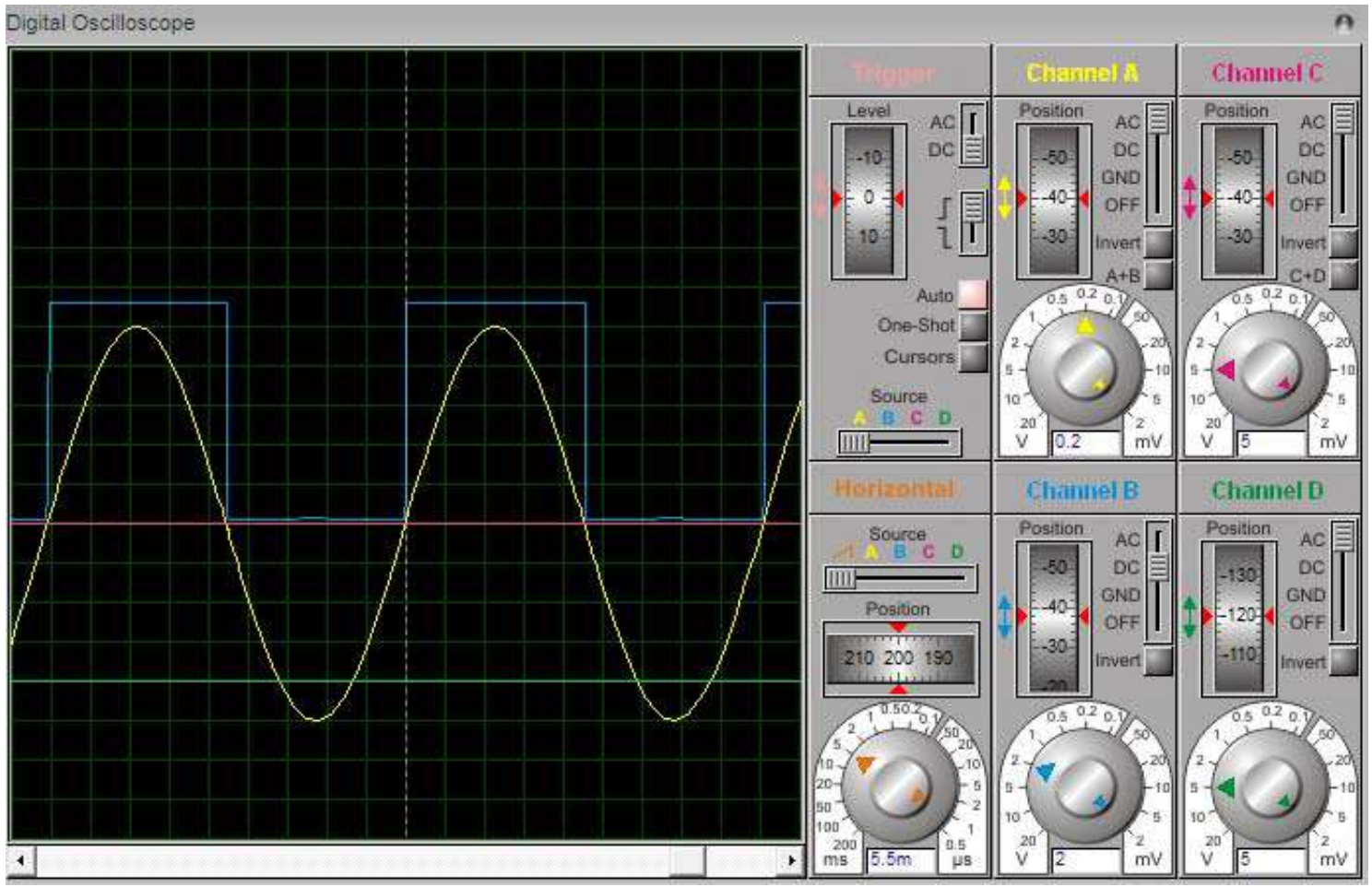

Fig-.4: output of the zero crossing detector circuit

For measuring AC power inductive and capacitive loads it is essentional to calculate power factor because for inductive and capacitive loads phase difference between voltage and current signal may not be exactly 90 degrees it may vary continuously. Due to this it causes power loss while measurement of power. Therefore it is necessary to find power factor to calculate power of inductive and capacitive devices. Main goal is calculating power factor is to calculate phase difference between current and voltage. In zero crossing detector circuit after Detecting the Zero Crossed points; square wave signals are obtained and applied to the $18 \mathrm{~F} 4550$ microcontroller which detect and sense these rising and falling edges (it depends on the written program for microcontroller operation which in this case falling is selected) and with its ability to set or reset the related counter/timers which calculates the time difference between these two signals. While calculating power factor Oscillator frequency, prescale values and timer values are selected according to microcontroller and timer calculation.. Figure 5 shows Phase Difference Calculation Procedure. 


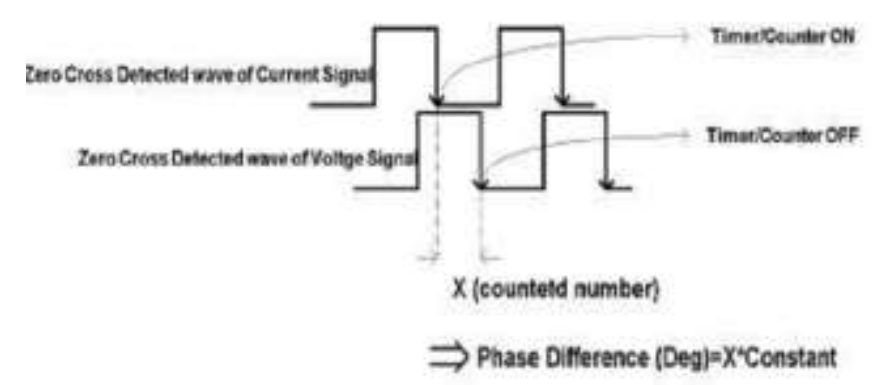

Fig-5: Phase Difference Calculation Procedure

As it is shown in Figure 5 Zero crossing detector circuit converts input sine wave into square wave output. when first the falling edge of current is detected that is connected to INT0 pin of microcontroller, timer/counter starts to count until it detects second the zero cross voltage signal that is connected to INT1 by using timer1 of $18 \mathrm{~F} 4550$ Microcontroller. After that it stops timer1 and calculate phase difference angle in degrees and display it on LCD. Angle can be calculated by using Mikroc software regarding selected prescale and oscillator values and timer calculation values.

\subsection{Multiplier Section}

The multiplier IC AD633 is the central element of the proposed system. AD633 can operate in four quadrant mode, that means both analog signals or operands that are multiplied can take any polarity $+/$ - and multiplication occur in four quadrants It has differential $\mathrm{X}$ and $\mathrm{Y}$ inputs and high impedance summing output. It can operate with supply voltage of $+15 \mathrm{~V}$ and $-15 \mathrm{~V}$. AD633 is a complete fourquadrant multiplier IC offered in low cost 8-lead SOIC and PDIP packages. AD633 can be used for applications such as modulation and demodulation, automatic gain control, power measurement, and frequency doublers. Output signals from $\mathrm{CT}$ and VT are given to $\mathrm{X}$ and $\mathrm{Y}$ input terminals of AD633 IC and at the output (at pin no.7) we can get input signals multiplied and divide by a scale factor of ten in analog form. Fig.6 shows AD 633 multiplier IC.

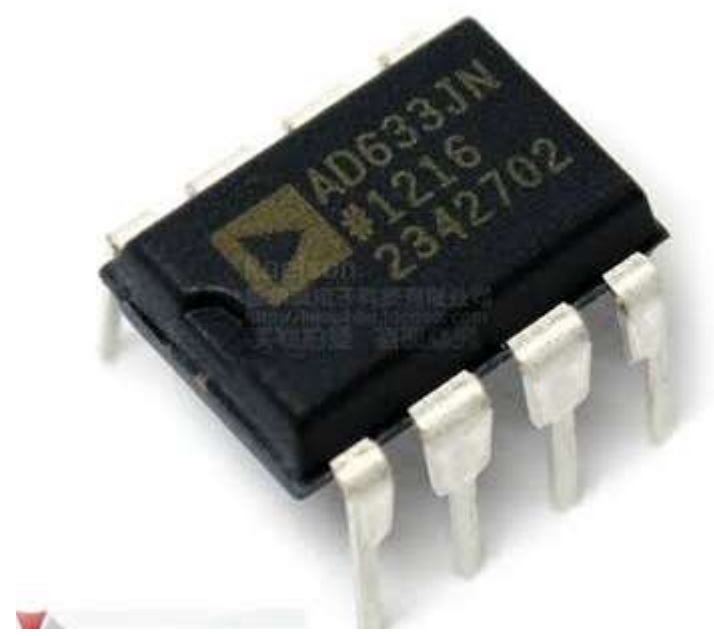

Fig-6: AD633 Multiplier IC

\subsubsection{Multiplier Connections}

Figure 7 shows AD633 multiplier used for multiplication for two analog signals the basic connections for multiplication. The analog voltage or current signals are applied to $\mathrm{X}$ and $\mathrm{Y}$ inputs and pin no.7 gives corresponding output analog signal by providing multiplication of two analog signals and dividing it by scale factor of ten.

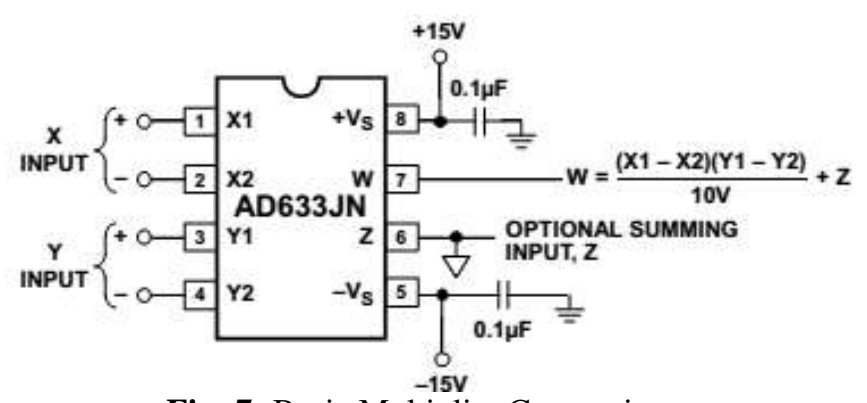

Fig -7: Basic Multiplier Connections

Figure. 8 shows the basic multiplication process simulation on Proteus

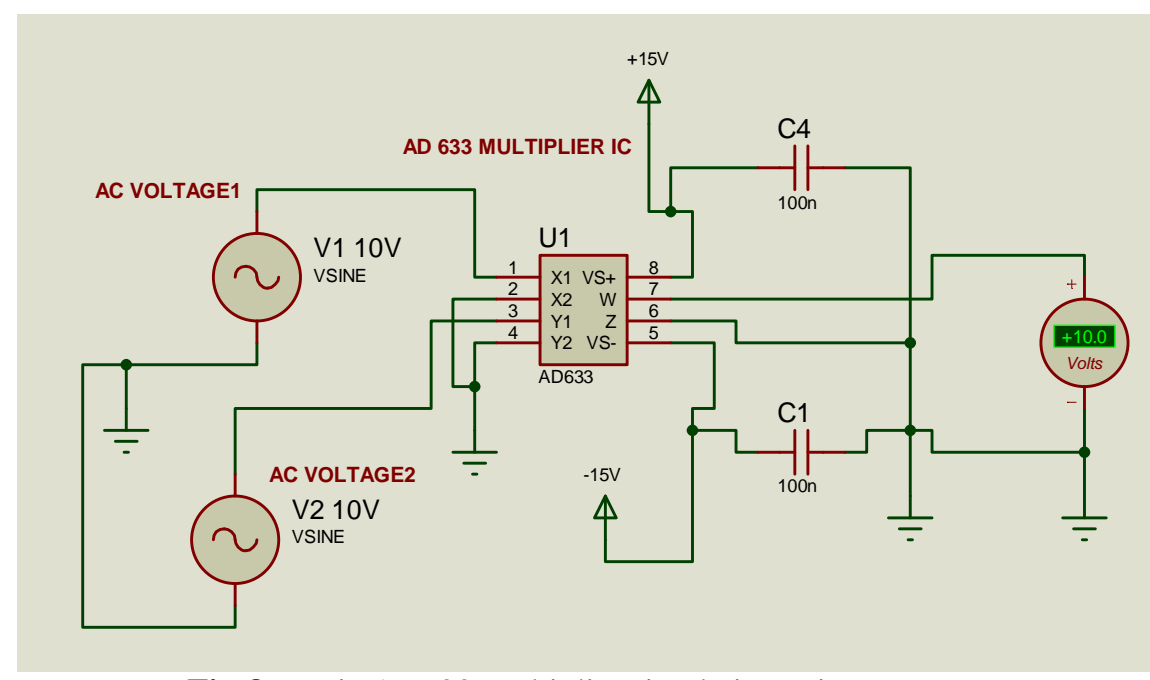

Fig-8: Basic AD633 Multiplier simulation using Proteus 


\subsection{PIC Microcontroller 18F4550}

The PIC18F4550, from Microchip is heart of the proposed system. It has 10 bit up to 13 channel inbuilt analog to digital converter (ADC) therefore it reduces extra circuitry to convert analog signal into digital signal. It can be programmed using MIKRO-C PRO and MPLAB complier. It has extended instruction set and 100,000 erase and write cycle architecture. The main advantage is that $18 \mathrm{~F} 4550$ microcontroller is a processor with built in memory and RAM so that there is no need to use separate external RAM, ROM and peripheral chips. One of important feature of PIC microcontroller is that we can re-program it as they can use flash memory and we can use ICSP serial interface built in each PIC microcontroller for programming. It can be programmed to provide interface for many devices.

Figure 9 shows PIC 18F4550 IC

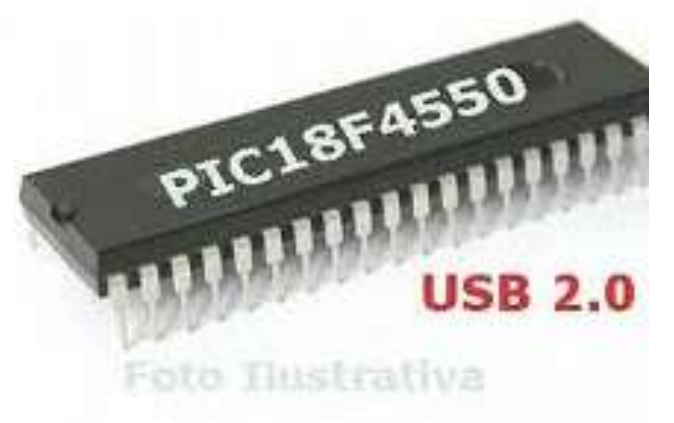

Fig-9: PIC 18F4550 IC

\subsection{LCD Display}

In this paper to display all parameters $16 \times 2$ LCD display is used.

\section{SOFTWARE IMPLEMENTATION}

Software Program is written in MIKRO-C PRO Complier and programmed using PICKIT3 programmer in PIC IC 18F4550. Basically program relates with finding with the phase difference between voltage and current under various load conditions and hence the Power Factor. In zero crossing detector circuit is used to detect when current signal and voltage signal are out of phase with each other (when zero is crossed). These signals are given to interrupt pins of the microcontroller. Microcontroller detects when first falling edge occur at INT0 pin and it starts Timer1. Similarly it detects when second falling edge occur on INT1 pin and it stops Timer1. According to decision making option to control whether a falling edge or rising edge exists on INT0 or INT1 pin, Timer1 will start therefore calculation of phase difference and power factor will be possible according to the frequency of the signals and selected prescale factor of the microcontroller. Software After power factor is find out output of AD633 that is given to ADC (AD0) pins of 18F4550 will read by Microcontroller to calculate power of AC load. Fig.10 shows software flowchart to calculate power factor.

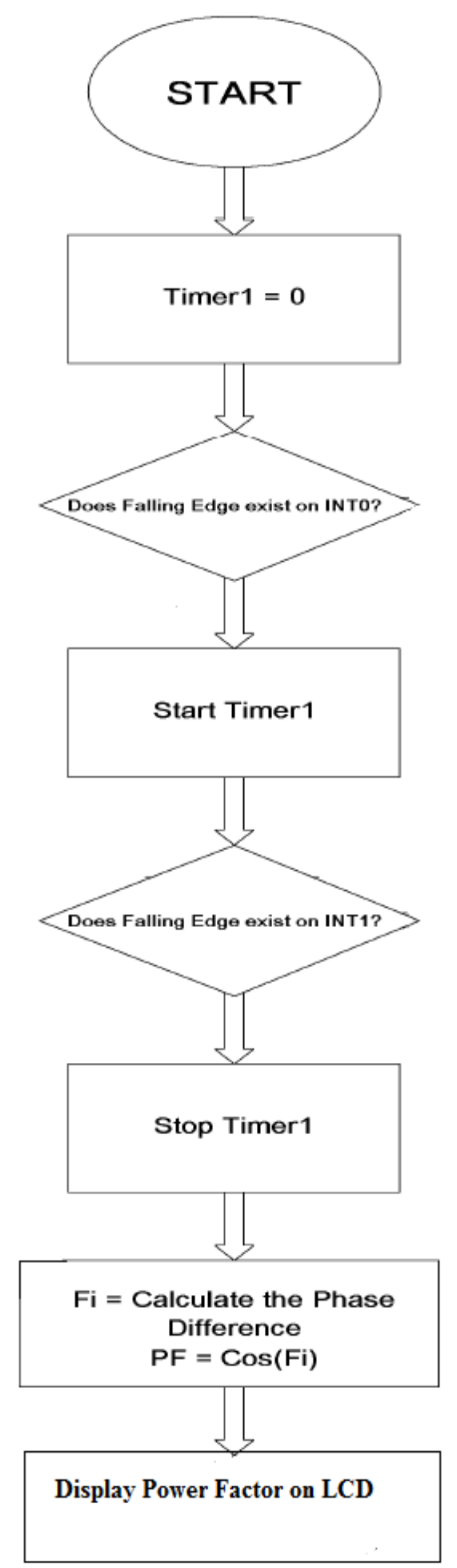

Fig-10: software flowchart to calculate power factor

\section{THE EXPERIMENTAL RESULTS}

The experimental results of the Instrument are shown in table1 as follows. These results are taken for different resistive loads under varying supply voltage, current and frequency. The proposed instrument has $1 \%$ or less than $1 \%$ of error for both resistive and inductive load. Proposed instrument has long life and can operate in both sinusoidal and non-sinusoidal condition of supply voltage with temperature range up to 65 degree Celsius. 
Table -1: showing test results for resistive load

\begin{tabular}{|l|l|l|l|l|l|}
\hline $\begin{array}{l}\text { Resistive } \\
\text { Load(W) }\end{array}$ & $\begin{array}{l}\text { CT Output } \\
\text { Voltage, (V) }\end{array}$ & $\begin{array}{l}\text { PT Output } \\
\text { Voltage (V) }\end{array}$ & $\begin{array}{l}\text { Output of AD 633 } \\
\text { at Pin 7 } \\
\text { (V) }\end{array}$ & $\begin{array}{l}\text { Output of Low pass } \\
\text { Filter (V) }\end{array}$ & $\begin{array}{l}\text { Observed Resistive } \\
\text { Load in (Watt) }\end{array}$ \\
\hline $100 \mathrm{~W}$ & $1.10 \mathrm{~V}$ & $10 \mathrm{~V}$ & $1.10 \mathrm{~V}$ & $0.25 \mathrm{~V}$ & $98 \mathrm{~W}$ \\
\hline $200 \mathrm{~W}$ & $2.30 \mathrm{~V}$ & $10 \mathrm{~V}$ & $2.30 \mathrm{~V}$ & $0.52 \mathrm{~V}$ & $202 \mathrm{~W}$ \\
\hline $300 \mathrm{~W}$ & $3.40 \mathrm{~V}$ & $10 \mathrm{~V}$ & $3.40 \mathrm{~V}$ & $0.72 \mathrm{~V}$ & $297 \mathrm{~W}$ \\
\hline $400 \mathrm{~W}$ & $4.30 \mathrm{~V}$ & $10 \mathrm{~V}$ & $4.30 \mathrm{~V}$ & $1.05 \mathrm{~V}$ & $408 \mathrm{~W}$ \\
\hline $450 \mathrm{~W}$ & $5.50 \mathrm{~V}$ & $10 \mathrm{~V}$ & $5.50 \mathrm{~V}$ & $1.08 \mathrm{~V}$ & $456 \mathrm{~W}$ \\
\hline $500 \mathrm{~W}$ & $6.10 \mathrm{~V}$ & $10 \mathrm{~V}$ & $6.10 \mathrm{~V}$ & $1.25 \mathrm{~V}$ & $510 \mathrm{~W}$ \\
\hline $600 \mathrm{~W}$ & $6.95 \mathrm{~V}$ & $10 \mathrm{~V}$ & $6.95 \mathrm{~V}$ & $1.55 \mathrm{~V}$ & $595 \mathrm{~W}$ \\
\hline
\end{tabular}

Also simulation test results are shown in fig. 11 and fig. 12 as follows

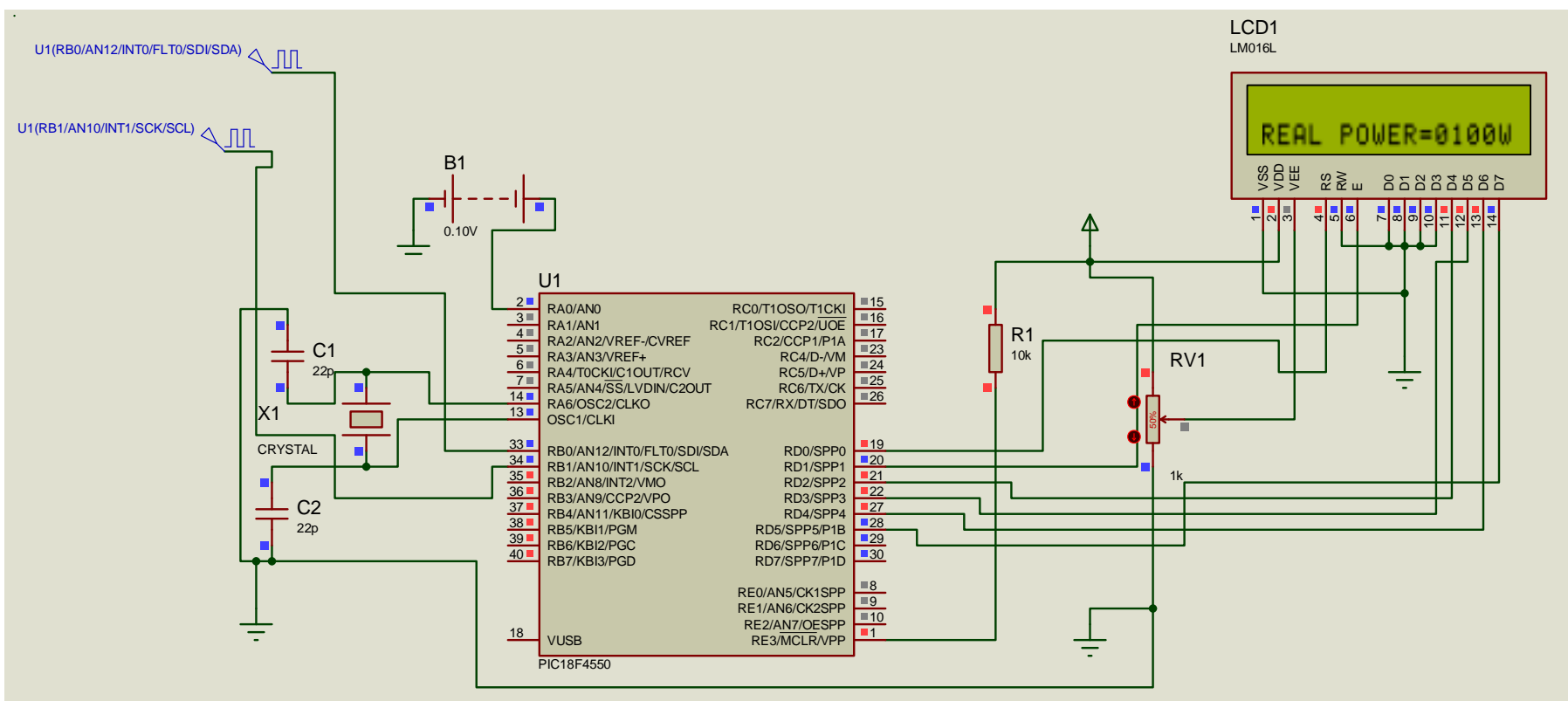

Fig-11: simulation results of measuring AC power in Proteus.

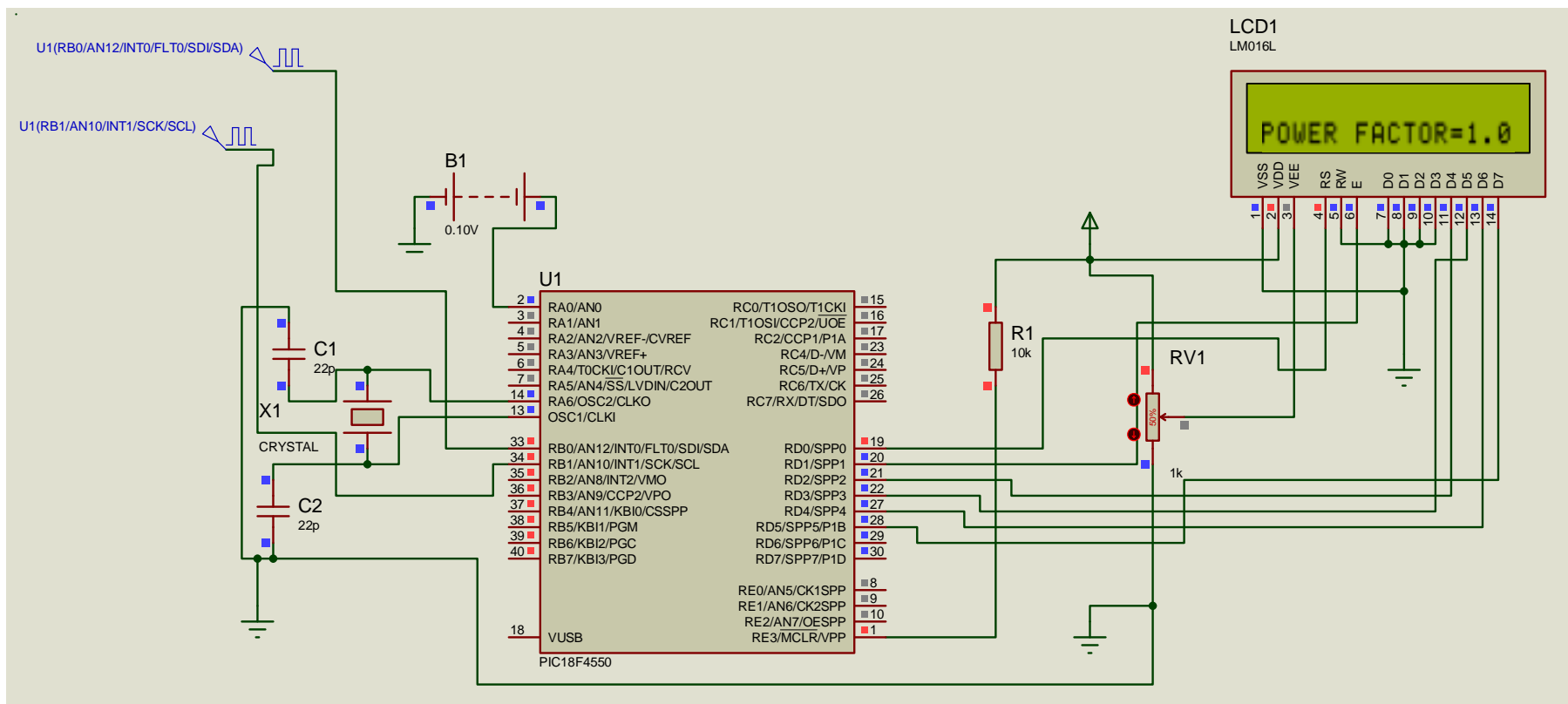

Fig-12: simulation results of measuring power factor in Proteus 


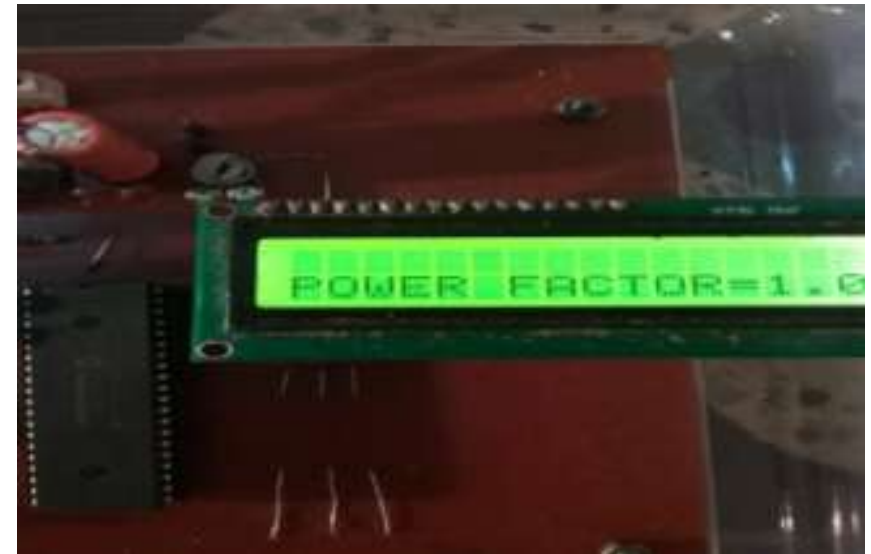

Fig -13: showing results of measuring power factor

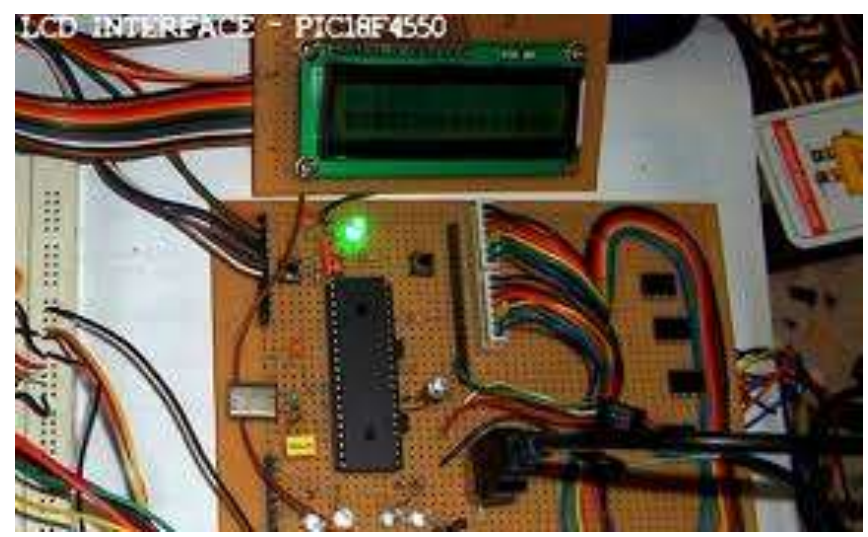

Fig-14: LCD interfacing with 18F4550 Microcontroller

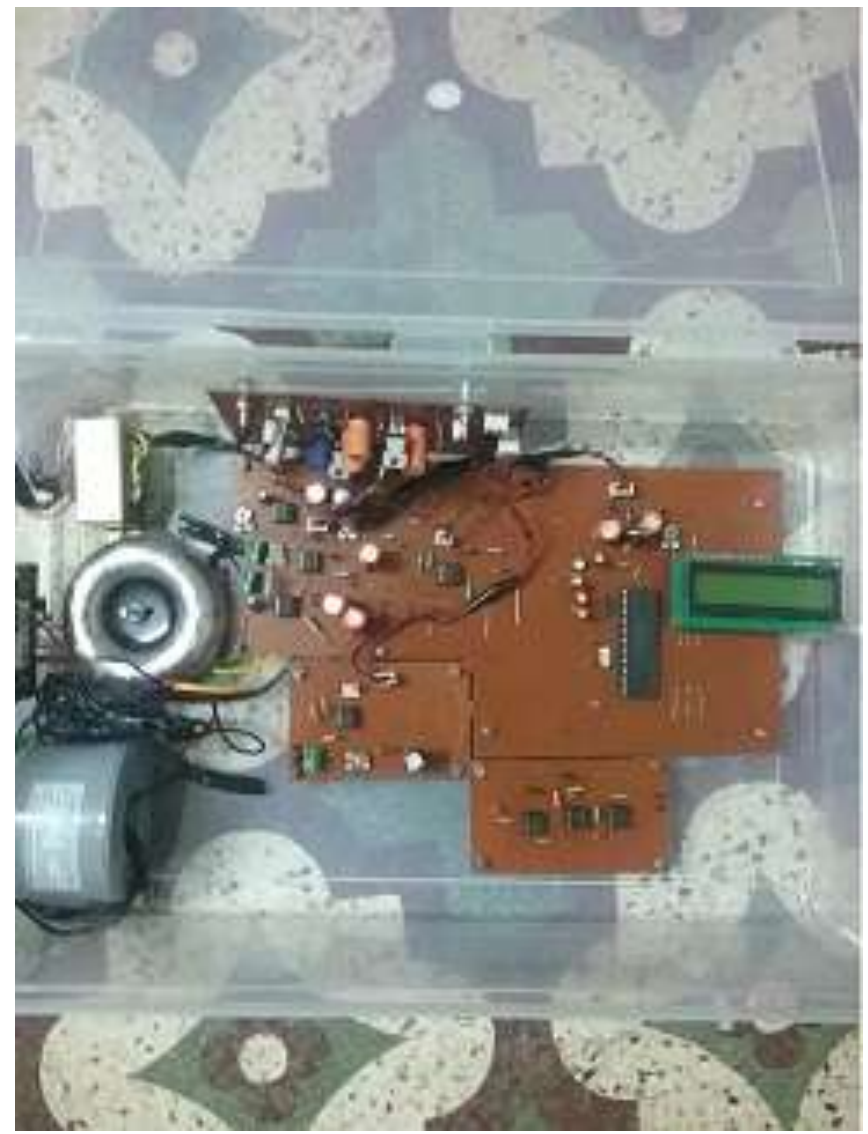

Fig-15: Actual hardware diagram of proposed project

\section{MERIT OF THE SYSTEM}

\subsection{Existing System}

Existing system includes various types of wattcmeters to measure the power in both $\mathrm{dc}$ and ac circuits, including thermo-responding, dynamometer. In all these wattmeter's voltage and current values are calculated and based on these values relative power can be calculated. Due to voltage and current fluctuations and supply voltage variations accuracy of these devices is reduced. So taking all these considerations proposed system is designed.

\subsection{Proposed System}

In the proposed system there is no need to calculate voltage and current values separately because AD633 directly multiplies voltage and current and gives average power. that is proportional to load. Also in proposed system power factor is calculated that is important in calculating power of inductive and capacitive loads. The main advantage of this system is that it is simple system and can be designed using easily available components. Overall cost of this design also is low.

\section{CONCLUSION}

Proposed wattmeter design is based on multiplying analog voltage and current signals using AD633 multiplier Ic to obtain power of various appliances and electrical devices. Experimental results are also shown in table1 and accuracy of this design is about $99 \%$ in both sinusoidal and nonsinusoidal voltage and current conditions. Also this design requires less computational effort and more simple in design. This wattmeter gives better performance in supply voltage, temperature and frequency variation.

\section{ACKNOWLEDGEMENT}

I would like to express our gratitude to our respected teacher Professor R.R.JAGTAP Professor, Department of E\&TC, ADCET, who inspired and motivated me to get my selves involved in this circuit design especially involving PIC microcontroller software coding and hardware implementation of this designs. His invaluable guidance help me lot to work up to this stage and complete this design.

\section{REFERENCES}

[1]. Salivahanan S, Bhaaskaran VSK (2008) Linear Integrated Circuits. Analog multipliers, Tata McGraw-Hill, New Delhi, India

[2]. Sawhney AK, Sawhney P. (2003) Electrical and electronics measurements and measuring instruments. Measurement and Measurement Systems.

[3]. C.-H. Lien, H.-C. Chen, Y.-W. Bai, and M.-B. Lin, "Monitoring and control for electric home appliances based on power line communication," in Proc. I2 MTC, Vancouver, Canada, May 2008, pp. 2179-2184.

[4]. Ramakant A. Gaykaward (2001); “Op-amps and Linear Integrated Circuits” Prentice-Hall India Third Edition. 
[5]. M. A. Mazidi, R.M. Kinlay \& D. Causey (2008); "PIC Microcontroller", Prentice Hall Inc., pp.24

[6]. A. Collins,Solid State Solutions for Electricity Metrology, Metering and Tariffs for Energy Supply, no. 462, May 1999.

[7]. E. Hayashi, "Electric power to de signal converter," Kabushikikaishi Yokogawa Denki, Appl. no. 843 504, Oct. 19, 1977, U.S. patent 4145652 Mar. 20, 1979.

[8]. P. S. Filipski, "A TDM wattmeter with $0.5-\mathrm{MHz}$ carrier frequency,"IEEE Trans. I M, vol. 39, no. 1, pp. 15-18, Feb. 1990.

[9]. Models 253311 and 153321 Digital Power Meter (Single-Phase ac and DC(AC), IM2533-01E, 4th ed., Yokogawa Electric Corporation, Mar. 1988, UP.

[10]. A. Kalinowski and R. Brockmann, "Hall plate wattmeter circuit including compensation for the Hall plate thermo-voltage," Philips Company, U.S. Patent 3250995 , May 10, 1966..

\section{BIOGRAPHIES}

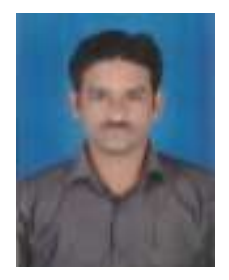

Alankar Mahadev Salunkhe is currently working as Escalation Executive (T.L.) at TCL Pune. He has total 3 years of teaching experience and 2 years of industrial experience. His area of interest is in Embedded system and Robotics. He is pursuing his M.E (VLSI \& EMBEDDED SYSTEM) from. Annasaheb Dange College of engineering and technology, ashta.

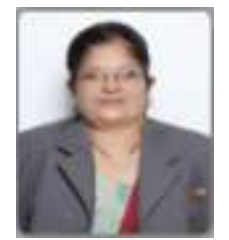

Prof.R.R.Jagtap received Master degree in Electronics with Shivaji University Kolhapur. She is currently working in Annasaheb Dange College of Engineering and Technology, Ashta. She has 14 years of teaching experience. Her area of interest is in Networking, Wireless, and Communication engineering. She is life member of ISTE. 